\title{
Remote Learning Experience of College Teachers in Israel during COVID-19 Pandemic
}

\author{
Lipaz Shamoa-Nir \\ Department of Behavioral Sciences, Zefat Academic College, Zefat (Safed), Galilee region, Israel.
}

\begin{abstract}
How to cite this paper: Lipaz Shamoa-Nir. (2022). Remote Learning Experience of College Teachers in Israel during COVID-19 Pandemic. The Educational Review, USA, 6(1), 22-27. DOI: $10.26855 /$ er.2022.01.003

Received: December 15, 2021

Accepted: January 10, 2022

Published: January 26, 2022

Corresponding author: Lipaz Shamoa-Nir, Department of Behavioral Sciences, Zefat Academic College, Zefat (Safed), Galilee region, Israel. Email: lipaznir@zahav.net.il
\end{abstract}

\begin{abstract}
Online education has evolved as an alternative to face-to-face classes during the COVID-19 pandemic both in schools and in higher education. The positive implications of planed remote learning have been explored however, online teaching in response to a disaster incur limitations especially, in sessions designed for educational staff training. This study explores experiences and perceptions of college teachers and instructors while participating in online sessions. Thematic analysis found two aspects arising from the participants' experience: (a) most of the participants struggled to overcome technical difficulties that undermined group intimacy; (b) learning was perceived by most of the participants as ineffective due to interpersonal communication problems and online facilitating issues. These findings provide more evidence to ineffectiveness of communication in online sessions. In addition, this study have implications for remote training programs for both, teachers and students, and the development of video conferencing as a mode of communication in professional contexts.
\end{abstract}

\section{Keywords}

Online learning, group session, teacher training, higher-education, zoom

\section{Introduction}

The complex reality during the COVID-19 pandemic and lockdowns has made online meetings the only feasible solution for group communication over large distances in many organizations (Steinicke, 2016). Schools and higher education institutions had to cenacle face-to-face classes, including labs, workshops and other learning experiences, and moved to online education using Zoom and other learning management systems. Indeed, moving online has had many benefits especially, enabled flexibility of teaching and learning anywhere and anytime (Barbour, 2010; Barbour et al., 2020). However, recent studies have suggested significant differences between well-planned online meeting experiences and sessions held in response to a crisis or disaster (Barbour et al., 2020). This study aims to explore participation of teachers in online training sessions especially, to analyze the impact of the transition to digitally-mediated communication and the meaning of this training as reflected in participants' experience.

The literature regarding educational technology has addressed several techniques that have been developed: distance learning, mobile learning, online learning and others (Irvine, 2020). Studies have indicated many benefits of online learning (Chingos \& Schwerdt, 2014; Means, 2010), however, it was argued that online learning is especially effective when it is planned and designed carefully in systematic models (Branch \& Dousay, 2015). Moreover, in emergency situations, these designed processes are absent hence; alongside the acknowledged advantages quite a few limitations are found. For example, recent study indicated several students' difficulties and limitations of online learning during 
COVID-19 pandemic (Mukhtar et al, 2020). I argue that participating in emergency online learning sessions may be especially challenging for educational staff. Thus, I use qualitative data to explore teachers' perceptions during online sessions, that is, how teachers describe their experience in their own words.

Online group communication often hinders spatial perception of full-body language, deictic relations, or eye-to-eye contact (Oeppen et al., 2020). Moreover, strategies of allocating attention and controlling attention change according to task demands (Gopher, 1999), so it is plausible that different strategies are employed in virtual meetings compared to face-to-face encounters, for example, approach and avoidance motor activations which affect prejudice towards outgroup members (Razpurker-Apfeld \& Shamoa-Nir, 2021). Virtual meetings require efficient perception of alternating displays, localizing popping voices and filtering out background visuals and noises.

In addition, virtual space is a fertile ground for a renewed expression of behaviors such as: acting out and anti-group phenomena (Steinicke, 2016). Sponsored by technology, such behaviors are represented by a variety of technical aspects: dark "picture slots" characterizing discoursing people; group members leaving video mode as meeting goes on, and returning to it after managing other duties or pleasure; leaving the meeting without turning off the camera, thus interrupting group communication; communicating via the legitimate chat option in the application for a private or public chat which may not always be relevant to the discussion, as long as the eye of the camera could not track the "misbehaved" group member.

\subsection{The current study}

The advantages and shortcomings of online group meetings in comparison to traditional meetings have been acknowledged (Webster \& Wong, 2008). However, using technologies for online group meetings deserves special attention when it occurs during an emergency time, e.g., pandemic. In particular since, during COVID-19 pandemic lockdowns such virtual meetings were compulsory, forcing experienced and novice users to connect through technology.

In addition, it has been well established that sensitivity to cultural backgrounds is an essential component in the development of professional growth of academic staff (Shamoa-Nir, 2014), especially, in colleges that are situated "on the periphery" of Israel. As these colleges primarily serve the people who live in this area, both the students and the teachers represent the various sectors and communities of this region (Shamoa-Nir, 2014). In should be noted that, the Israeli society is consist of Jews-majority (73.9\% of the population), and Arab-minority which is divided into a number of religious affiliations (18\% Muslim, 1.5\% Christians, and 2\% Druze, in relation to the whole population). Moreover, interactions between the groups are held in a social context in which the socio-economic status of the Arab minority is lower in education, employment and wages compared to Jewish majority. Hence, education in this multicultural setting promotes dialogue between groups (Shamoa-Nir, 2014), and incorporates the idea that all students, regardless of their religion, gender, or cultural characteristics are entitled to receive an equal opportunity for education (Banks \& McGee Banks, 2001). Therefore, online education can be considered as an effective model for equal opportunity for education in these multicultural settings (Banks \& McGee Banks, 2001). Nevertheless, more practical knowledge is needed in order to develop strategies for the implementation of these notions in training programs, especially online session for academic staff. Thus, the aim of this study is to explore how college teachers and instructors experienced the emergency online work sessions during the first COVID-19 pandemic lockdowns; to explore attitudes and emotions that arose during the sessions, and whether attending the sessions has contributed to their learning.

\section{Method}

\subsection{Participants \& Procedure}

These data are part of a larger study on experiences and attitudes during the first lockdowns (March-May 2020) of COVID-19 pandemic in Israel. I gathered 63 comments from open internet chats (of four different sessions) in which there were 49 participants (14-20 in each session). All participants were Jewish and Arab teachers living and working in colleges in Israel, 28 were female and 21 were males. All participants took part in these group sessions as part of their professional work and in order to maintain teaching and instruction during the COVID-19 pandemic. The online meetings were tailored training sessions intended to support the transition to online teaching. The sessions were facilitated by professional faculty members in the field of distance learning. All participants were teachers who are experienced in facilitating face-to-face lessons and meetings. The participants wrote their impressions; thoughts and reflections during the online sessions and voluntarily shared their experience and insights in internet open chats. All the names were changed in this article to protect participants' anonymity. 


\subsection{Analysis strategy}

The data were analyzed based on procedures delineated by Bryman (2004) in the following manner: First, analysis was conducted on an initial set of 10 comments, which were closely studied for themes by the author and a faculty member, separately. Then, the coding scheme was used to analyze all the comments and the presence or absence of relevant themes in each comment was marked. After deciding which three themes to proceed, a coding scheme for was developed, and the remaining comments were analyzed. The analysis reported in this research is based on the author coding.

\section{Results}

Most of the comments (80\%) addressed difficulties in relation to the virtual arrangement of online work meetings which have been imposed by the COVID-19 pandemic mainly because the participants were actually locked down at home. Three themes emerged in the way participants expressed their experiences and attitudes during the online meetings. They mainly reflect the conditions which were expected by the participants to contribute to the communication and the learning however in fact, delayed them.

\subsection{The difficulty to gain group intimacy}

Most of the participants (75\%) indicated foundational aspects of video conferencing (e.g. creating eye contact, invasion of privacy etc.) as obstacles to gain group intimacy. In fact, unlike face-to-face meeting in which each person is free to choose a sitting position, be it by the facilitator or next to a friend; in an online meeting "physical proximity" is replaced by other aspects affecting "psychological closeness”. For example, Rachel described:

While I was happy to watch my colleagues on screen, I could not make eye contact with them, and they felt remote, even when virtually interacting with them. And so I found myself drifting between alienation to proximity and connection with participants, some of whom were silent, surprised or terrified, while the other were talkative, experienced and confident. I also wondered about the impact of visual display on the experience of the other participants, especially given the option to choose one of several displays.

Even though about $80 \%$ of the participants addressed the physical distance as an obstacle to psychological closeness between participants (reflected in a variety of aspects), they were aware of the effects of the remote meeting and tried adjust this new format. For example, Sara wrote:

Sitting comfortably in my house in my familiar room, I was observing many faces that seemed to have invaded my home. Fifteen to twenty staff members attended each meeting, most of the time. Slowly, amid the fears and defenses, there came passion and curiosity for acquiring new skills. At the same time, as I was taking part in a well-recognized activity framed within a new technology, social behavior was reflected in my thoughts. I was curious about my own social behavior and that of others, whether and how it was modified in comparison to face-to-face group practice. I examined ways of coping with a new communication channel while observing and learning.

\subsection{Remote learning: Sense of competition and ineffective communication}

Most of the participants' negative experiences (80\%) were attributed to the challenges of learning a new platform or mode of interaction. These participants have supported the transition to online training however, did not feel they had significant learning. About half of them criticized the group process in particular, communication between the participants during the meetings. Thus, it seems that overcoming technological troubleshooting to enable meeting attendance brought about quite a few humanly drawbacks which cannot be engineered to an instant solution and caused frustration among the participants, as Mira wrote:

During this lockdown, I have been forced to attend several online faculty meetings and training sessions arranged by the college in which I teach. Like everything else during these hectic days, this new online learning format seemed strange too, and sessions originally designed for circular seating positions were replaced by positioned "heads in cubes" on screens [...] this experience was very different from participating in face-toface group meetings that enable significant learning and group process[...] this meeting was not effective and cannot replace face-to-face communication.

More than half of the participants (60\%) experienced difficulties to speak during the meetings referred the communi- 
cation in terms of "competition” and "survival”, as David wrote:

At first it seems that there is an advantage here because in the online meeting equal opportunities were given to all participants to speak, thanks to a presetting of volume and allowing each voice to be heard separately at any given moment. This is, of course, on condition that you were able to unmute the microphone in time. I came to know that, as in nature, a survival struggle threatened equal opportunities: those who were faster or higher in vocal volume took a more significant place in discussions.

Moreover, the participants referred to the ineffectiveness of the learning and the group process in light of the "low quality of communication" and the discussions, e.g. Moshe wrote: "It was hard to understand the instructor and sometimes impossible to express myself or to really listen and understand the other speakers, not just technically but rather to give and get real attention”. In addition, most of the participants (70\%) complained that the continuity of the learning and discourse that took place at the meeting was not possible. Yael wrote: "In the end of scheduled time, meeting is ended and I found myself staring immediately at a faceless screen, not being able to discuss the issues and process I had undergone”.

\subsection{Adjusting to online facilitation}

About $70 \%$ of the participants noted that "the instructor did not create comfortable conditions for learning", however, they did not directly oppose the facilitator who is a "faculty member in our status" and a "colleague". As a result, these participants described the online encounter as a frustrating experience without the ability to express themselves properly, as Debra wrote:

Using the outstanding function of "mute all" they marvelously enforced order. It answered my need for having a responsible character to restore order and guide us, especially given the existential anxiety and disruption of order in our new lives when COVID-19 is out there. However, there was also my need to trust the facilitator. But how could I have not doubted the facilitator who did not allow me or my colleagues to raise a legitimate discourse by muting us all? Such an act left me frustrated, angry and insulted.

According to some of the participants, at times, facilitators could not be visible or present. They were absent from important discussions due to technical reasons, such as lapses of communication or electricity. There were participants who specifically addressed the relationship with the facilitator of the online session, as Amos wrote:

On the one hand, we saw the facilitator in his domestic territory, which provided a sense of intimacy, which most likely would not occur in an actual meeting. In addition, facilitator was very prominent when his image display was enlarged, and in addition to being persistently present, he was also seen very clearly. So clearly that they seemed close, and we could focus on his face and observe his facial expressions. On the other hand, participants could not see the body language of the facilitator and had to rely mainly on clues revealed by faces.

\section{Discussion}

This study explores teachers' perceptions regarding participation in online sessions during emergency situation. A thematic analysis was used to analyze comments and descriptions of teachers' learning experience in online sessions via Zoom or Webex. The findings indicated that participating in the online meetings has been a challenging and frustrating experience for most of the participants who criticized the online learning process for being ineffective and with poor communication between participants. In particular, the participants indicated lack of equality in meetings since they were unable to speak freely due a competition and struggles over "talk time". The participants' negative experiences were not attributed to the overall emergency situation, but mainly to the challenges of learning a new platform or mode of interaction, and to the essential aspects of learning through online communication.

The participants views centered on group communication and facilitating issues. The participants criticized the facilitators for not meeting the variety of their needs, and thereby creating uncomfortable conditions and ineffective group process. It seems that this criticism involved an inevitable comparison to face-to-face meetings. Previous studies have argued that technology enables facilitators and teachers more management and control than in face-to-face meetings (Antonello et al., 2020). For example, facilitators can mute all participants when discussions are out of hand, and they can control participants entering and leaving the group. Facilitators have a free choice to use these options or not. These benefits, of learning online, were not reflected in the experience of the participants in this study. In addition, it 
was argued during face-to-face meetings, even when meeting is adjourned, the informal discussions keep flowing and are professionally appreciated, almost as much as participating in the meeting itself (Shamoa-Nir, 2017a; Shamoa-Nir, 2022). This enables enriching learning, which according to the current findings were missing in the online sessions.

The findings of this study may indicate a dual learning experience as a result of a tension between two conflicting views; on the one hand, supporting online teaching due the acknowledged benefits of online education (Barbour, 2010), and on the other hand, experiencing ineffective communication due to lack of intimacy and alienation alongside efforts to interact with limited social closeness. That is, the advantages of online education associate with frustration among the participants. Indeed, previous studies have indicated several limitations of online learning both, technological and psychological, especially online meetings during a pandemic were more stressing for students (Antonello et al., 2020). However, this study suggests more evidence of teachers' difficulties in participating "as students" in distance learning. It seems that, when teachers participate in online training "as students" their experiences reflect mainly negative attitudes which reduce most of the benefits of online learning.

In addition, it should be noted that the multicultural campuses in which this study teachers work are affected by social tensions arising due to the ethic-religious Israeli-Palestinian conflict (Shamoa-Nir, 2014; Shamoa-Nir \& Razpurker-Apfeld, 2020b). Moreover, previous studies in this setting have indicated ingroup favoritism among children (Shamoa-Nir et al., 2021) and adults (Shamoa-Nir, 2017b), alongside negative attitudes towards Arab/Jewish out-group members (Razpurker-Apfeld \& Shamoa-Nir, 2020; Shamoa-Nir \& Razpurker-Apfeld, 2019a; Shamoa-Nir \& Razpurker-Apfeld, 2019b; Shamoa-Nir \& Razpurker-Apfeld, 2020a). However, unlike previous findings, the intergroup conflict did not arise at all in the responses of participants, teachers, and facilitators, who were from both ethnic groups. A possible explanation for this finding may be the teachers' perceptions regarding the lack of informal space to discuss and digest what happened during the online sessions. Nevertheless, it seems that the participants managed themselves in this conflict-affected setting, by focusing on their difficulties of coping with learning in the new method.

The limitations of the study stem from its being based on an analysis that was conducted on data received from a relatively a small sample of online sessions. This makes generalization of the study findings challenging. However, the personal and detailed comments which were gathered produced findings with depth which contribute to our understanding of the process that college teachers go through during participation in these sessions. Nonetheless, a study with a larger sample is recommended as a follow-up study, especially online learning during emergency times. Moreover, the multicultural context in which the present study was conducted emphasizes the equal opportunity for education (Banks \& McGee Banks, 2001) thus; experiences of remote learning among participants from different ethno-religious backgrounds should be further investigated.

This study offers an interesting counterbalance to techno-optimistic vision of technology use mainly by showing how participating in online meetings involves an inevitable comparison to face-to-face meetings (Webster \& Wong, 2008) and thus, holds a constant tension between closeness and alienation, and between comfort and difficulty. Reflected by these tensions, online learning is a challenging experience that does not necessarily entail only benefits for both, teachers and learners, and may turn out to be a masterwork. These findings contribute to the understanding that schools and colleges working to maintain online teaching should consider expectations and needs of learners in online sessions, especially those designed in response to a crisis or disaster. More broadly, this study may contribute to the professional context that uses video conferencing as a common mode of communication.

\section{Acknowledgements}

The author thanks the teachers who participated in the internet chats.

\section{References}

Antonello, V. S., Panzenhagen, A. C., Balanzá-Martínez, V., and Shansis, F. M. (2020). Virtual meetings and social isolation in COVID-19 times: transposable barriers. Trends in psychiatry and psychotherapy, 42(3), 221-222.

Banks, J. and Banks, C. A. M. (2001). Multicultural Education, Historical Development, Dimensions and Practice. En J. a. Banks, Handbook of Research on Multicultural Education, 3-29.

Barbour, M. (2010). Perspectives on E-Learning: Development and Challenges of K-12 Online Learning. In Society for Information Technology \& Teacher Education International Conference (pp. 310-315). Association for the Advancement of Computing in Education (AACE).

Barbour, M. K., LaBonte, R., Hodges, C., Moore, S., Lockee, B., Trust, T., and Kelly, K. (2020). Understanding pandemic pedagogy: differences between emergency remote, remote, and online teaching. State of the Nation: K-12 e-Learning in Canada. 
Branch, R. M. and Dousay, T. A. (2015). Survey of instructional design models. Association for Educational Communications \& Technology. Indiana: AECT.

Bryman, A. (2004). Qualitative research on leadership: A critical but appreciative review. The leadership quarterly, 15(6), 729-769.

Chingos, M. M. and Schwerdt, G. (2014). Virtual schooling and student learning: Evidence from the Florida Virtual School. Cambridge, MA: Harvard Kennedy School. Retrieved Oct, 25, 2014.

Gopher, D. (1993). The skill of attention control: Acquisition and execution of attention strategies. In D. E. Meyer \& S. Kornblum (Eds.), Attention and Performance XIV: Synergies in Experimental Psychology, Artificial Intelligence, and Cognitive Neuroscience (pp. 299-322). Cambridge, MA: MIT Press.

Irvine, V. (2020). The landscape of merging modalities. EDUCAUSE Review, 10.

Means, B. (2010). Technology and education change: Focus on student learning. Journal of Research on Technology in Education, 42(3), 285-307.

Mukhtar, K., Javed, K., Arooj, M., and Sethi, A. (2020). Advantages, Limitations and Recommendations for online learning during COVID-19 pandemic era. Pakistan Journal of Medical Sciences, 36(COVID19-S4), S27.

Oeppen, R. S., Rutherford, E., Sadler, P., Isaac, R., and Brennan, P. A. (2020). Virtual ARCP assessment and trainee feedback meetings: facilitating the best experience and practice. British Journal of Oral and Maxillofacial Surgery.

Razpurker-Apfeld, I. and Shamoa-Nir, L. (2020). Imagined contact with a stereotypical outgroup member: Effects of intergroup attitudes and anxiety on intergroup expectancies. Asian Journal of Social Psychology, 23(4), 384-396. DOI: 10.1111/ajsp.12412.

Razpurker-Apfeld, I. and Shamoa-Nir, L. (2021). Is an outgroup welcome with open arms? Approach and avoidance motor activations and outgroup prejudice. Journal of Experimental Psychology: Applied, 27(2), 417.

Shamoa-Nir, L. (2014). Defining resilience from practice: Case study of resilience building in a Multi-Cultural College. Procedia Economics and Finance, 18, 279-286.

Shamoa-Nir, L. (2017a). A dialogue with the 'self': Identity exploration processes in intergroup dialogue for Jewish students in Israel. Learning, Culture and Social Interaction, 13, 1-10.

Shamoa-Nir, L. (2017b). The window becomes a mirror: the use of the Johari Window model to evaluate stereotypes in intergroup dialogue in Israel. Israel Affairs, 1-20.

Shamoa-Nir, L. (2022). "Under the Radar”: How is the Jewish-Arab Conflict Reflected in Internal Jewish Dialogue? International Journal of Psychological Studies, 14(1). DOI:10.5539/ijps.v14n1p16.

Shamoa-Nir, L. and Razpurker-Apfeld, I. (2019a). Religious Primes and Threat-Perceptions as Predictors of Attitudes toward Muslims in Israel. Integrative Psychological and Behavioral Science, 1-24.

Shamoa-Nir, L. and Razpurker-Apfeld, I. (2019b). Investigating Stereotypes Towards the Outgroup: The Role of Religious Concepts and Group Membership. Basic and Applied Social Psychology, 41, 188-200.

Shamoa-Nir, L. and Razpurker-Apfeld, I. (2020a). Investigating stereotypes among minority group members in Israel: The role of ingroup and outgroup symbols. The American Journal of Psychology, 133(2), 169-180. DOI: 10.5406/amerjpsyc.133.2.0169.

Shamoa-Nir, L. and Razpurker-Apfeld, I. (2020b). The impact of exposure to religious symbols on intergroup anxiety. Israel Affairs. DOI: $10.1080 / 13537121.2020 .1832333$.

Shamoa-Nir, L., Razpurker-Apfeld, I., Dautel, J. B., and Taylor, L. K. (2021). Out-group prosocial giving during childhood: The role of in-group preference and out-group attitudes in a divided society. International Journal of Behavioral Development, 45(4), 337-344.

Steinicke, F. (2016). Being Really Virtual. Springer.

Webster, J. and Wong, W. K. P. (2008). Comparing traditional and virtual group forms: identity, communication and trust in naturally occurring project teams. The International Journal of Human Resource Management, 19(1), 41-62. 